\title{
The Impact of Concrete Pavement Field Floor to Vehicle Missile Launching Process
}

\author{
Wei Xinlin, ${ }^{1}$ Jiang Yi, ${ }^{1}$ Zeng Wei, ${ }^{2}$ and Ni Xiaochuan ${ }^{1}$ \\ ${ }^{1}$ Beijing Institute of Technology, Beijing, China \\ ${ }^{2}$ China Academy of Launch Vehicle Technology, Beijing, China \\ Correspondence should be addressed to Wei Xinlin; 286522979@qq.com
}

Received 7 April 2017; Revised 26 November 2017; Accepted 3 December 2017; Published 31 December 2017

Academic Editor: Nicolas Avdelidis

Copyright (c) 2017 Wei Xinlin et al. This is an open access article distributed under the Creative Commons Attribution License, which permits unrestricted use, distribution, and reproduction in any medium, provided the original work is properly cited.

\begin{abstract}
The conception and evaluation indices of the bearing capacity of the concrete pavement field floor are analyzed in this paper. In order to get the damage process of the concrete panel, its tension and compression injury factors are derived, and a field floor structural dynamic model with concrete damage constitutive relation is built based on ABAQUS, and the influence of thickness and Young's modulus of the concrete panel to the vehicular missile launching is comparatively analyzed.
\end{abstract}

\section{Introduction}

Missile launching is an important component of the whole launching process, with the features of greater load and shorter time. Severe vibration takes place on the launch platform under the joint effect of impact of ejection load and flexible support of the field floor, which has an important influence to the missile's initial disturbance. Excessive initial disturbance will make the plume impact to the launch canister laterally when the missile engine is ignited, causing damage to launch platform in extreme conditions. Therefore, it is required to study the influence to the launch effects of the coupling effect of launch equipment and field floor.

The stretch and compression effects of the vertical cylinder were considered, and the major incentive load during the launching process was discussed, including the ejection force, additional load, and contact force. The launching dynamic model of flexible effects with field floor was established, the simulation analysis of the launching dynamics was carried out, and the impacts of concrete panel thickness and elastic modulus to the launching effects were discussed in detail.

\section{Conception and Evaluation of Carrying Capacity}

When choosing the launching field floor for vehicular missiles, it is primary to ensure that the field floor will not be damaged from accessing the position to evacuating after the entire launching process was completed; secondly, the subsidence cannot be too much in order to avoid inclination of launching equipment. The evaluation of the field floor carrying capacity should focus on the security of missile launching and the critical state (limit state). The limit state of field floor carrying capacity is the state when pavement structural stress exceeds the material strength and then damage it or when excessive deformations influence the launching process.

Since 1960, Losberg and others have developed the theory of ultimate bearing capacity of concrete pavement structures on the basis of yield line theory [1]. In 1963, Meyerhof proposed a method for estimating the ultimate bearing capacity of rigid plastic plates on elastic foundations [2].

Damage of the field floor is related to thicknesses, materials of each structural layer, and the conditions and loads between the layers closely. For the rigid concrete field floor, the concrete surface layers bear the major loads. The process from applying the loads to damaging layers completely can be divided into four stages [3], as is shown in Figure 1. The ultimate bearing capacity of the road slab proposed by Meyerhof is calculated with the stage 3 of the panel work, which is the limit load when the top surface appears to have a circular crack. All the linear elastic modes are calculated by stage 2 of the panel work, when the first radial crack occurs at the bottom of the panel [3]. 


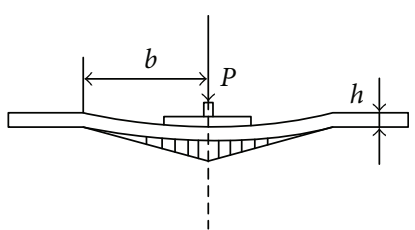

FIGURE 1: A schematic diagram of rigid pavement carrying loads.

Stage 1: apply the load $P$. The stress on the pavement panel does not exceed the ultimate strength of it. The panel is in elastic state. After stopping the load, the pavement panel restores.

Stage 2: increase the load $P$ gradually. The flexural tensile stress in the central part of pavement panel reaches the flexural tensile strength firstly, and radial cracks occur in this part. Then, the load applied on the panel is called yield load $P_{s}$, which can be considered as the maximum load in the elastic stage.

Stage 3: increase the load continuously. The cracks generated firstly begin to expand and stretch, and meanwhile more radial cracks appear, which extend radially from the center of the panel, until the flexural tensile stress is produced by the maximum negative moment in the position with a distance of $b$ from the center.

Stage 4: as the load continues to increase, the cracks grow larger. Until the panel is sheared along the cracks and sinks, the panel is totally destroyed.

As can be seen from the destruction process of the pavement panel, it is the center of the panel bottom that cracks firstly, of which the stress reaches the flexural tensile strength firstly. To ensure that the field floor would not be damaged during launching, the flexural tensile stress should be monitored. Thus, the flexural tensile stress of the panel bottom should be one of the indicators that expresses carrying capacity. Deng and Chen [3] defined the ultimate carrying capacity of the pavement structure as the pavement deflection in the critical failure state. Pavement deflection essentially contains the composite deformation of every layer of pavement structure, characterizing the capability of pavement layers to resist the vertical deformation and reflecting the overall stiffness of the subgrade pavement structure, considering the deflection evaluation can help to prevent excessive deformation of the field floor that will cause subsidence. In summary, in order to prevent the floor's holistic cracking and excessive deformation of the floor surface, the flexural tensile stress of the center of the bottom surface of field floor and the deflection of its top surface are defined to be the evaluation indicators.

\section{Dynamic Analysis of the Launching Process}

3.1. Stiffness Calculation of Hydraulic Cylinders. After erecting in place, the positive and negative pressure chambers of the cylinder are all in closed state. The hydraulic oil is generally considered not to be compressible, but its compressibility cannot be ignored if there is great dynamic load.

There are two cases in the launching process of the hydraulic cylinder, stretched state and compressed state. In the stretched state, the resistance is mainly contact forces due to spacing between the piston cylinders. In the compressed state, the piston rod moves to the side of positive pressure chamber, and the oil under pressure generates resistance. Then, the erection cylinder functions as a very large spring with a great stiffness and damping, as shown in Figure 2.

Viscous damping coefficient is related to selection of the hydraulic oil. The viscous damping coefficient of piston is taken as $250 \mathrm{~N} \cdot \mathrm{s} / \mathrm{mm}$ based on the simulation validation study of erecting process of large-scale installations [4]; equivalent hydraulic stiffness is calculated $[5,6]$ as

$$
K=\frac{A^{2}}{V} E,
$$

where $\mathrm{A}$ is the effective area of hydraulic compression, $\mathrm{V}$ is the volume of oil chamber, and $\mathrm{E}$ is the elastic modulus of hydraulic, usually taken as $750 \mathrm{MPa}$.

According to the effective area and volume of chambers, equivalent stiffness of each stage is calculated as $3.9 \times 10^{7} \mathrm{~N} /$ $\mathrm{m}, 3.96 \times 10^{7} \mathrm{~N} / \mathrm{m}, 4.02 \times 10^{7} \mathrm{~N} / \mathrm{m}$, and $4.08 \times 10^{7} \mathrm{~N} / \mathrm{m}$.

The erecting hydraulic system comprises four hydraulic cylinders, so the spring dampers are added between the piston and cylinder to simulate the compression of hydraulic cylinders when establishing the launching dynamic models.

3.2. Incentive Load. The vehicular missile uses draping ejection mode in this study. Throughout the launching process, the main motivations the missile suffered are the ejection forces of ejection devices and the impact forces between adapters and canister, and the main motivations the launching devices suffered are additional loads generated by the adaptive base, the collision force, and the coupling force of the field floor.

3.2.1. Ejection Force. The ejection force of the missile is provided by the launcher, which is simulated by unidirectional force with body in ADAM. Its magnitude is

$$
F(t)=P(t) \cdot S
$$

where $P(t)$ is the experiment measurements of gas pressure at each time, as shown in Figure 3; $S$ is the effective area at the bottom of the missile.

3.2.2. Additional Loads of Adaptive Base. Ejection power system uses adaptive base gas ejection system. Prior to launch, the adaptive base is suspended at a distance from the launching field floor. During the launch, expansion and deformation occur to the base in the role of high-pressure gas and then the base comes into contact with the ground, transmitting the recoil force to the ground through the adaptive base. However, not all the gas pressure is transmitted to the ground. There is a part of the load acting on the launching canister, which is called additional load. Additional load is an input parameter simulating the ejection process and has significant influence to launching effect. It is also an important input parameter to design the launch canister and initial container chamber. The structure of adaptive base is shown in Figure 4. 


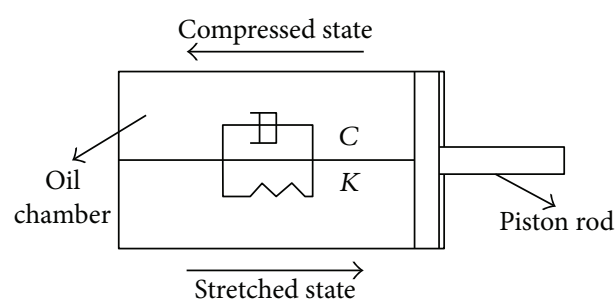

FIGURE 2: A schematic diagram of stiffness calculating a hydraulic cylinder.

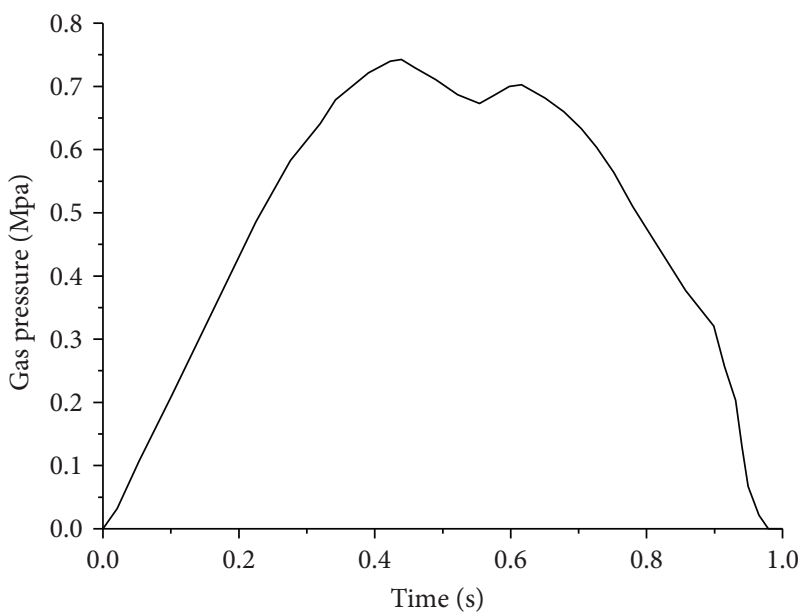

FIGURe 3: Gas pressure curve.

Currently, the additional load was measured by the combined empty release test of the pressure buildup in the initial chamber [7]; there is no mature theoretical calculation method of additional loads. The finite element method is used for calculation in this study. The ABAQUS software is used to simulate the expansion of the adaptive base and its contact process with the field floor under launching conditions. Then, we integrate the tensile stress on the upper end face of the base to obtain additional load.

Adaptive base material is a composite that comprises cord and rubber, of which the inner and outer surfaces are rubber material with a thickness of $0.5 \mathrm{~mm}$. Its internal part is of laminated plate structure of 15 layers $\pm 45^{\circ}$ alternate plies. Rubber material is simulated by constitutive model Yeoh provided by ABAQUS, of which the model parameters refer to the value in literature [7]. The elastic modulus of cord is taken as $767 \mathrm{MPa}$ [8]. The S8R unit is used to discrete the base, and the Reber unit simulates the enhancement of cord in rubber, establishing the structural dynamic model according to Table 1. ABAQUS/explicit display solver is used for calculation; the sampling frequency is $10 \mathrm{~Hz}$. The finite element model established in ABAQUS are shown in Figure 5. Due to a certain fluctuation of the additional load, it is polynomially fitted, and the calculation results are shown in Figure 6.

3.2.3. Contact Force. Throughout the launch process, the adapters will contact with the canister; thus, there is a request

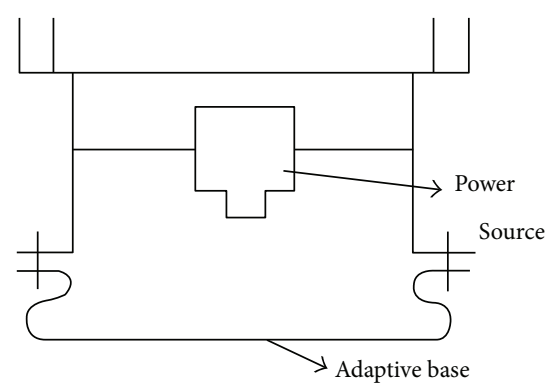

FIgURE 4: A schematic diagram of elastic system.

to establish contact relationships between these two entities. The adapters are set to be foam, and the canister be glass fiber composite material. The contact parameters are selected as follows recommended by ADAMS:

Contact stiffness is $3.8 \times 10^{3} \mathrm{~N} / \mathrm{mm}$; damping coefficient is $1.52 \mathrm{~N} \cdot \mathrm{s} / \mathrm{mm}$.

Force function index is 2 ; maximum penetration depth is $0.1 \mathrm{~mm}$.

Static friction coefficient is 0.13 ; dynamic friction coefficient is 0.09 .

Static friction conversion speed is $0.1 \mathrm{~mm} / \mathrm{s}$; dynamic friction conversion speed is $10 \mathrm{~mm} / \mathrm{s}$.

3.3. Calculation Results and Analysis. According to the above process, the flexible multibody dynamic model of vehicular missile weapon system is established in ADAMS, shown in Figure 7.

3.3.1. Dynamic Analysis of the Launching Process. The missile launching process at the basic structure of field floor is simulated here, obtaining the velocity of the missile, the dynamic response at the hydraulic legs, the vibration of canister top, and the initial disturbance of missile and other launching effects.

In order to describe the dynamic characteristics of the missile weapon system in the process of erecting and launching, the following coordinate system is set up.

The global coordinate system is an inertial coordinate system $O X Y Z$ and is connected with the earth. The original point is located at the origin of the datum coordinate system of the vehicle assembly in the three-dimensional modeling Pro/E. Axis $x$ points to the front of the vehicle, and axis $y$ is perpendicular to the direction of the field. Axis $z$ is determined by the right-hand rule.

The measurement coordinate system is a body coordinate system $o_{i} x_{i} y_{i} z_{i}, i=1,2, \ldots, 52$, and numbering of 52 components. The origin of the coordinate system is located at the center of the corresponding component, and the initial direction of each axis is consistent with the inertial coordinate system.

The missile uses vertical launching mode, The angular displacement of the missile around the inertial coordinate system $x$-, $y$-, and $z$-axis is defined as the yaw angle $\theta_{x}$, pitch angle $\theta_{y}$, and roll angle $\theta_{z}$. The angular velocity of the missile around the inertial coordinate system $x$-, $y$-, and $z$-axis is 
TABLE 1: Basic parameters of field structure.

\begin{tabular}{lcccc}
\hline Layer number & Layer material & Compression modulus $(\mathrm{MPa})$ & Poisson ratio & Thickness $(\mathrm{cm})$ \\
\hline 1 & PCC & 30,000 & 0.15 & 22 \\
2 & Cement-stabilized gravel & 4000 & 0.3 & 20 \\
3 & Lime soil & 2000 & 0.3 & 20 \\
4 & Compacted subgrade & 40 & 0.3 & - \\
\hline
\end{tabular}

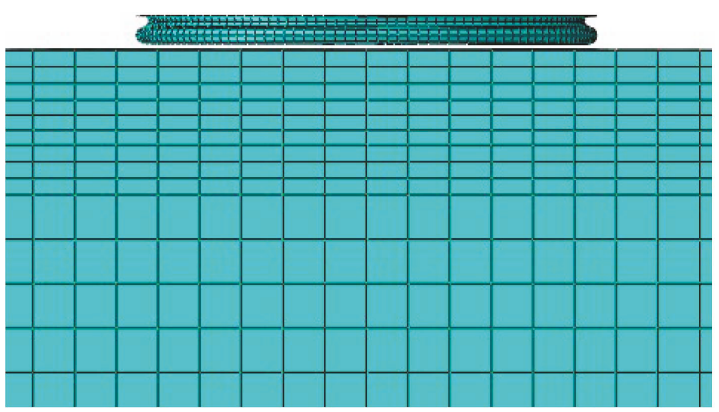

Figure 5: FEM of the base.

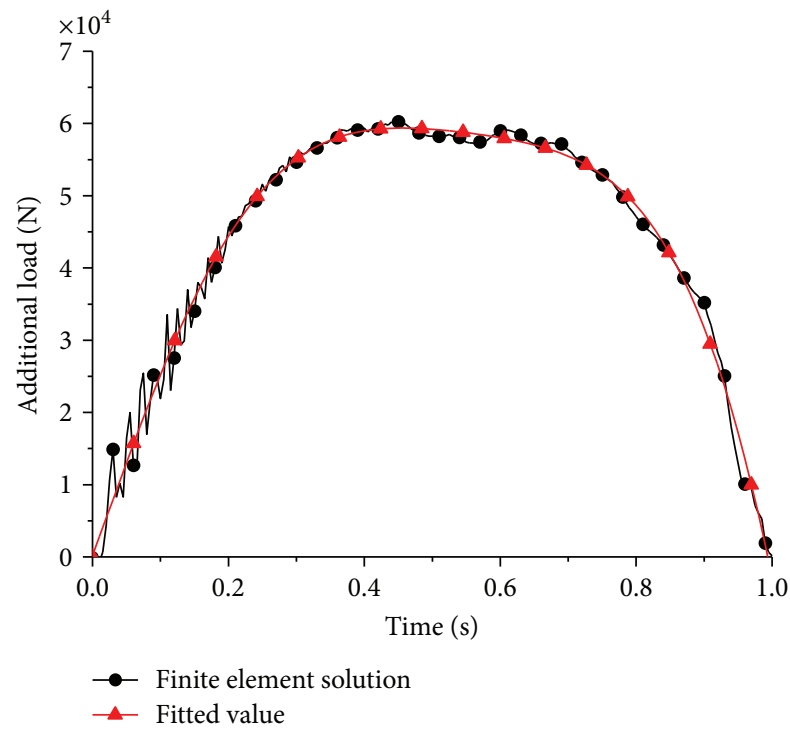

Figure 6: Additional load force.

defined as the yaw angular velocity $\omega_{x}$, pitch angular velocity $\omega_{y}$, and roll angular velocity $\omega_{z}$.

The simulation results are as follows:

Figure 8 is a curve showing the missile's velocity of centroid during the launching process. Figure 9 is a curve showing the angular velocities of the missile in pitch, yaw, and roll directions. Observing the animation process of simulation, it can be seen that the moment the missile leaves, the launching canister is $1.063 \mathrm{~s}$. According to Figure 8, the speed at which the missile leaves the canister is $25.49 \mathrm{~m} / \mathrm{s}$, and the maximum speed is $26.6 \mathrm{~m} / \mathrm{s}$, corresponding to the time of 0.939 . The information shows that before the missile leaves the canister completely, the ejection force exerted on it is not sufficient to overcome its weight and the friction from adapters, so the missile starts to do deceleration. After it is completely out of the canister, the missile makes uniform deceleration due to its own gravity.

As can be seen in Figure 9, the missile roll rate is almost zero; the yaw rate is very small, of which the maximum is only $0.047 \mathrm{deg} / \mathrm{s}$; the pitch angular velocity changes dramatically. The curve in resonance form indicates that the missile moves in reciprocating pitch ways. The maximum of the pitch angular velocity is about $1.06 \mathrm{deg} / \mathrm{s}$ and is $0.43 \mathrm{deg} / \mathrm{s}$ when the missile leaves the canister. The pitching movement of the missile is violent while the yawing and rolling movement is slight. The reasons are as follows: the draped ejection launching mode is used, and the additional load with respect to the fulcrum below of the launching arm forms a moment applying to the canister, making the canister do pitching under the "flexural" coupling effect of the field floor, and then the missile within the canister moves following it. As is also shown in Figure 9, the missile after leaving the canister bears only the gravity, and it will continue to rotate at the angular velocity of the moment it leaves the canister, which is adverse to the ignition of the missile.

Figure 10 shows the vibration velocities in $\mathrm{X}, \mathrm{Y}$, and $\mathrm{Z}$ directions of the center of top launching canister top; its vibration displacements in $\mathrm{X}, \mathrm{Y}$, and $\mathrm{Z}$ directions are shown in Figure 11. $x$-axis points to the right front of the vehicle, $z$-axis is perpendicular to the field floor and points upwards, and $y$-axis is determined by the right-hand rule.

It is apparently shown in Figure 10 that there is almost no vibration of the canister in $\mathrm{Y}$ direction, which is consistent with the law shown in Figure 9. In the $\mathrm{Z}$ direction, the canister has an upward movement with a small margin, which is a reflection of vehicle's overall "rebound" due to the launching platform that no longer bears the mass of the missile after it leaves. As can be seen from changes in $\mathrm{Z}$ direction, the rebound motion basically stopped after $t=1.3 \mathrm{~s}$, and the launch vehicle remains stationary in the $\mathrm{Z}$ direction. In the $\mathrm{X}$ direction, the launch canister is always in vibration state during launching. When the vibration in $\mathrm{Y}$ direction in Figure 10 is compared with the pitching angular velocity in Figure 9, the two curves are almost identical, which further explains that during the launch process, the pitch movement of the missile is caused by the pitch of launch canister, and the ring adapter around the missile has a significant effect in buffering.

Observing the curve in $\mathrm{X}$ direction in Figure 11, it can be seen that the vibration of launch canister weakens gradually and eventually maintains a forward offset of about $23 \mathrm{~mm}$. The reason is that the launch canister no longer bears the weight of the missile and rebounds after the missile launches. 


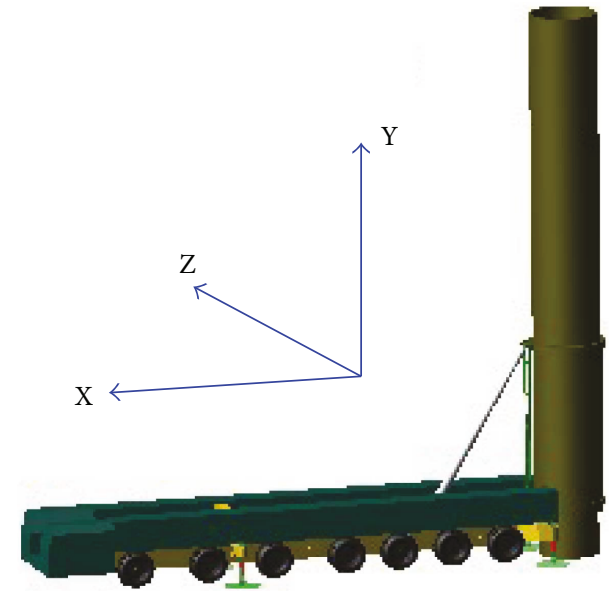

FIGURE 7: Launching dynamic model of vehicular missile weapon system.

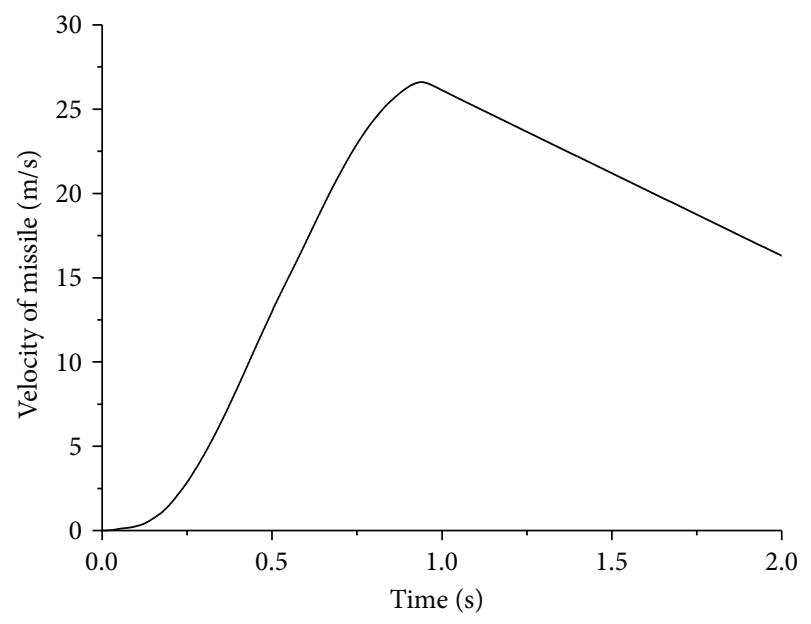

FIgURe 8: Missile velocity curve.

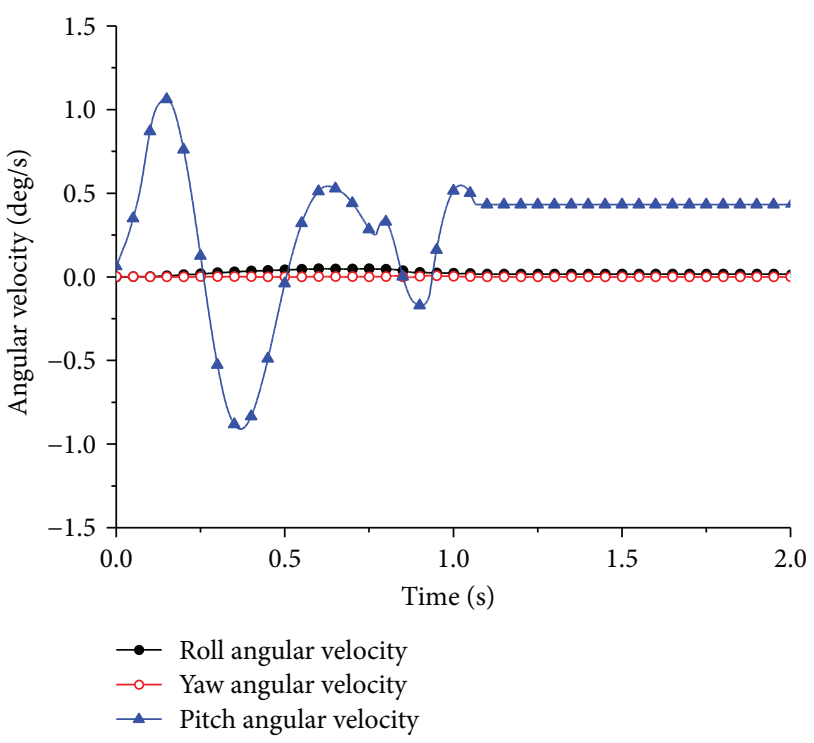

Figure 9: Missile angular velocity curve.

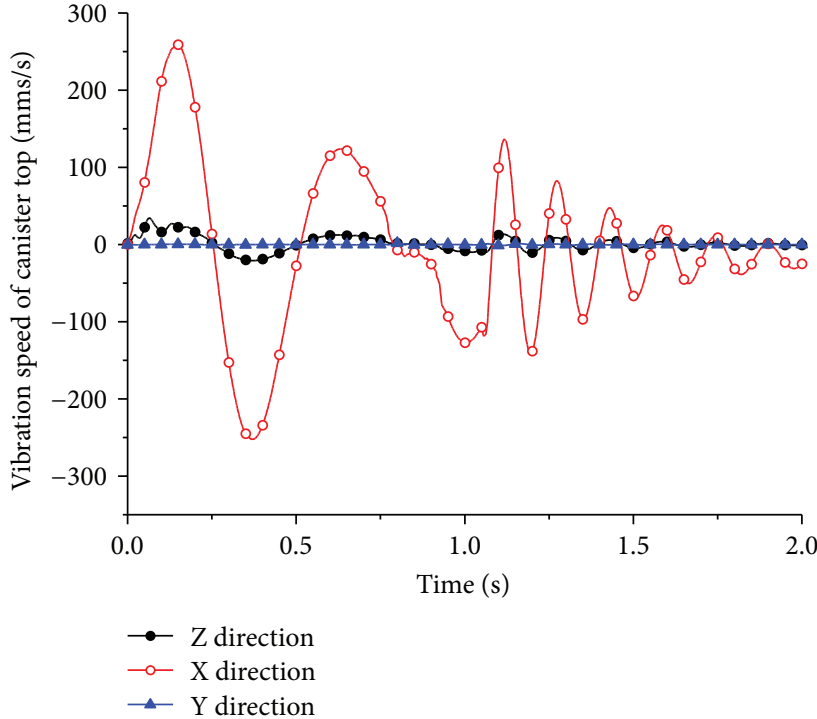

FIGURE 10: Vibration velocity of the launch canister top.

The contact forces in normal, longitudinal, and tangential direction are shown in Figures 12-14, respectively. As can be seen in Figure 12, the supporting force of the front and rear legs is not the same at the initial time of simulation for the fact that before launching, the missile is located at the rear of vehicle in vertical state, shifting the centroid of launch platform backwards. Changes in the supporting force value of rear legs show that the missile starts accelerated motion since $t=0.068 \mathrm{~s}$ when the ejection force increases to the missile's weight; when $t=0.1 \mathrm{~s}$, the base of the missile separates from the launch canister and continues to accelerate under the ejection force. During this period, the force applied to launch the vehicle by the missile decreases gradually, making the front and rear legs rebound gradually. When the launch platform no longer bears the weight of the missile, the centroid of the whole platform shifts forward drastically and it begins pitching in the inertia force. This fact is illustrated by the alternation between the pre and after $0.1 \mathrm{~s}$ of the contact force in the front and rear legs. After the missile leaves the canister, the vibration of the launch platform attenuates gradually until it stops due to the damping effect from itself and the field floor, and the force exerted on the field floor by the front and rear legs is $1.84 \times 10^{5} \mathrm{~N}$ and $1.4 \times 10^{5} \mathrm{~N}$, respectively.

From Figures 13 and 14, it can be seen that throughout the process of missile launch, there are certain vibrations in longitude and lateral directions of the launch platform, which decreases gradually until the missile is out of the canister. As can be seen in comparison of vibration amplitude in Figure 12, the maximum contact force in longitudinal direction is $1840 \mathrm{~N}$, and the maximum of the lateral contact force is $1687 \mathrm{~N}$, illustrating that the main vertical vibrations of the platform during the launch process as a result of what the launch platform suffered are mainly vertical loads including the weight of the missile, the friction caused by ejection, and the additional loads; and the longitude loads are mainly the passive friction from the field floor. 


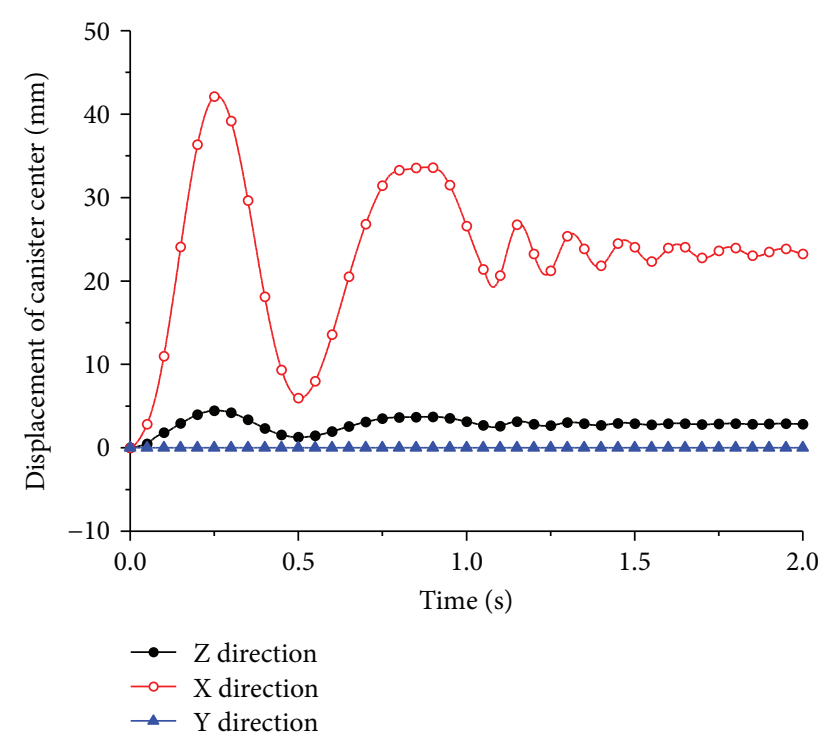

FIGURE 11: Vibration displacement of the launch canister top.

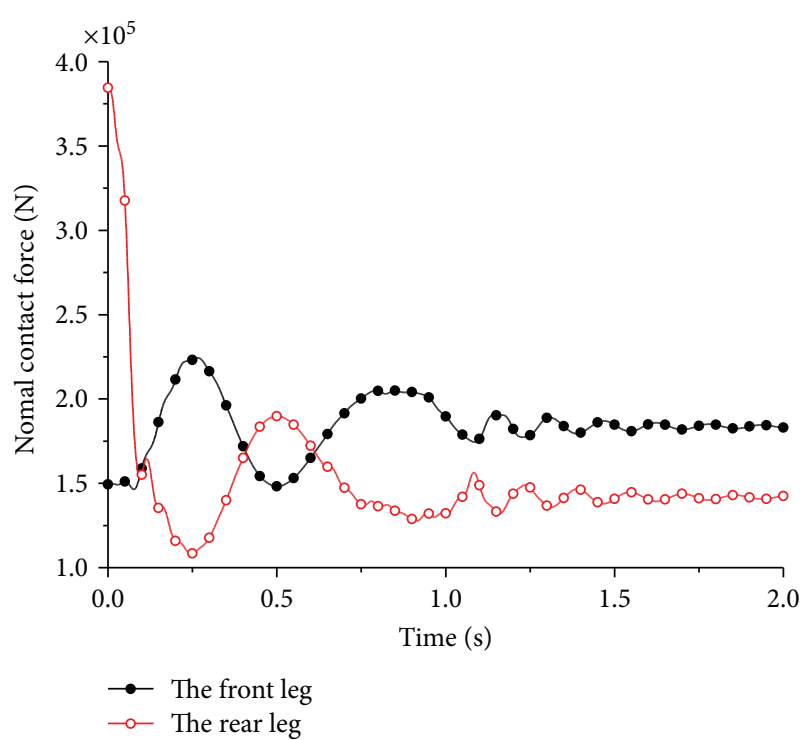

FIGURE 12: Contact force of legs in the normal direction.

3.3.2. Influence of the Concrete Surface Layer Thickness on Launch Effects. Pavement panel thickness is an important parameter to characterize the mechanical properties of the highway, which influence the support stiffness of the pavement to some extent, resulting in a significant impact on the launching process. Therefore, it is necessary to discuss the influence on the missile launching process of concrete panel thickness. Initial disturbance of missile and vibration of launch platform are mechanical behaviors that launching dynamic mainly focuses on and are also the main parameters reflecting the launch effects. So the changes of these two parameters in different panel thicknesses are mainly analyzed here. Assuming that the thicknesses of the surface layer are $50 \mathrm{~mm}, 100 \mathrm{~mm}, 150 \mathrm{~mm}$, and $200 \mathrm{~mm}$, for the convenience of the analysis, the simulations in these four thicknesses are defined in order as thickness 1, 2, 3 and 4, and the thickness

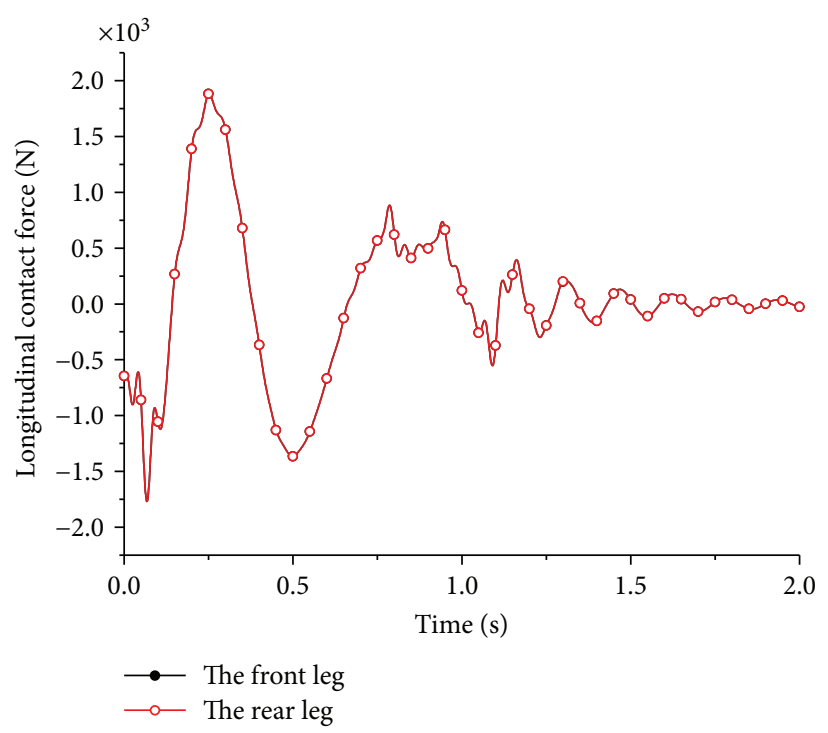

FIgURE 13: Contact forces of legs in the longitudinal direction.

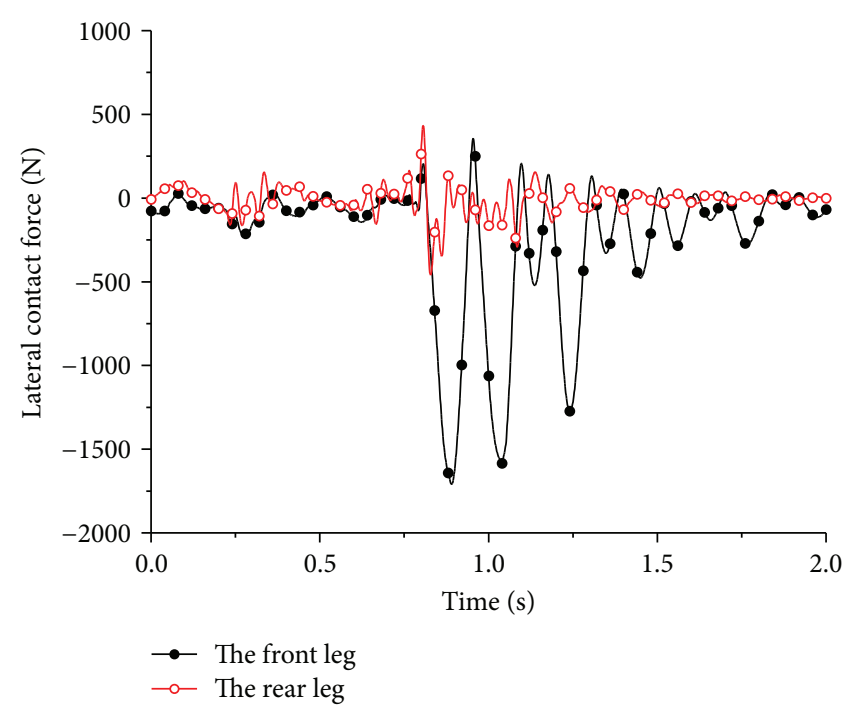

Figure 14: Contact force of legs in lateral direction.

4 is treated as reference to do a comparative study, the results are as follows.

Figure 15 shows curves of the missile in different surface layer thicknesses, in which the curves are almost identical, and their maximum velocities are all $26.6 \mathrm{~m} / \mathrm{s}$; Table 2 shows the effect of surface thickness on average velocity and final velocity, explaining that the concrete surface layers have no influence on the velocity at which the missile leaves the canister.

The pitch angular velocities and pitch angles of the missile are shown, respectively, in Figures 16 and 17 in different surface layer thicknesses. As the curves show, the pitch angular velocities and pitch angles of the missile in different surface layer thicknesses are not the same. At the moment, the missile leaves the canister, the pitch angular velocity in thickness $1,2,3$, and 4 is $0.819 \mathrm{deg} / \mathrm{s}, 0.756 \mathrm{deg} / \mathrm{s}, 0.486 \mathrm{deg} / \mathrm{s}$, and $0.453 \mathrm{deg} / \mathrm{s}$, respectively. Compared with thickness 4 , the 


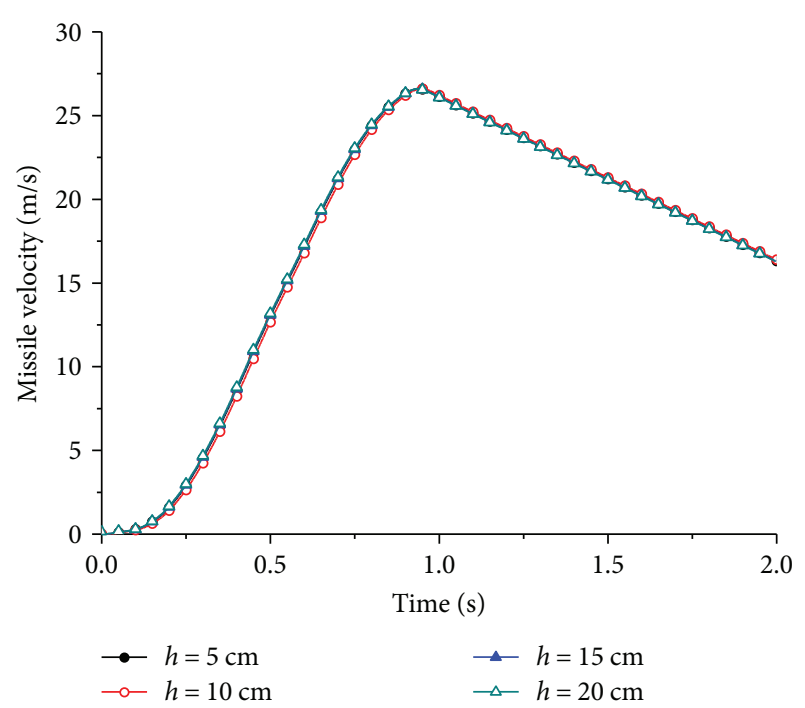

Figure 15: Missile velocity curves of different surface thicknesses.

TABLE 2: The effect of elastic modulus on velocity.

\begin{tabular}{lcc}
\hline Surface thicknesses $(\mathrm{cm})$ & $\begin{array}{c}\text { Average velocity } \\
(\mathrm{m} / \mathrm{s})\end{array}$ & $\begin{array}{c}\text { Final velocity } \\
(\mathrm{m} / \mathrm{s})\end{array}$ \\
\hline 5 & 17.11 & 16.31 \\
10 & 17.04 & 16.32 \\
15 & 17.13 & 16.31 \\
20 & 17.14 & 16.30 \\
\hline
\end{tabular}

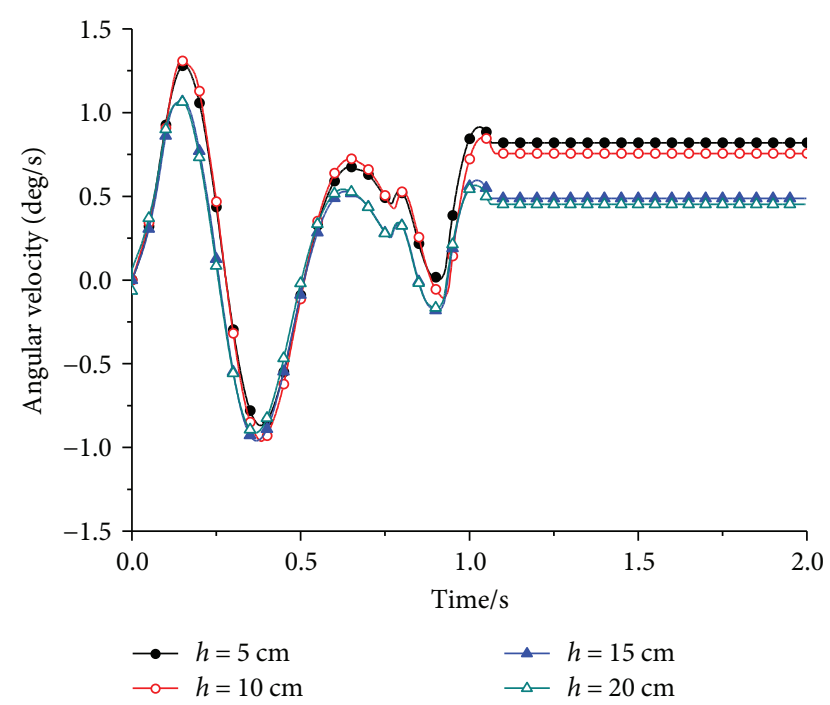

FIGURE 16: Pitch angular velocity of the missile in different surface layer thicknesses.

pitch angular velocity of thickness 1,2 , and 3 increases $80.80 \%$, $66.89 \%$, and $7.30 \%$, respectively. The pitch angles are $0.235 \mathrm{deg}, 0.228 \mathrm{deg}, 0.207 \mathrm{deg}$, and $0.197 \mathrm{deg}$ and increase $19.30 \%, 15.70 \%$ and $5.10 \%$, respectively, compared with thickness 4 . For thickness, thickness 1,2 , and 3 reduces $75 \%, 50 \%$, and $25 \%$ compared with thickness 4 , respectively. As can be

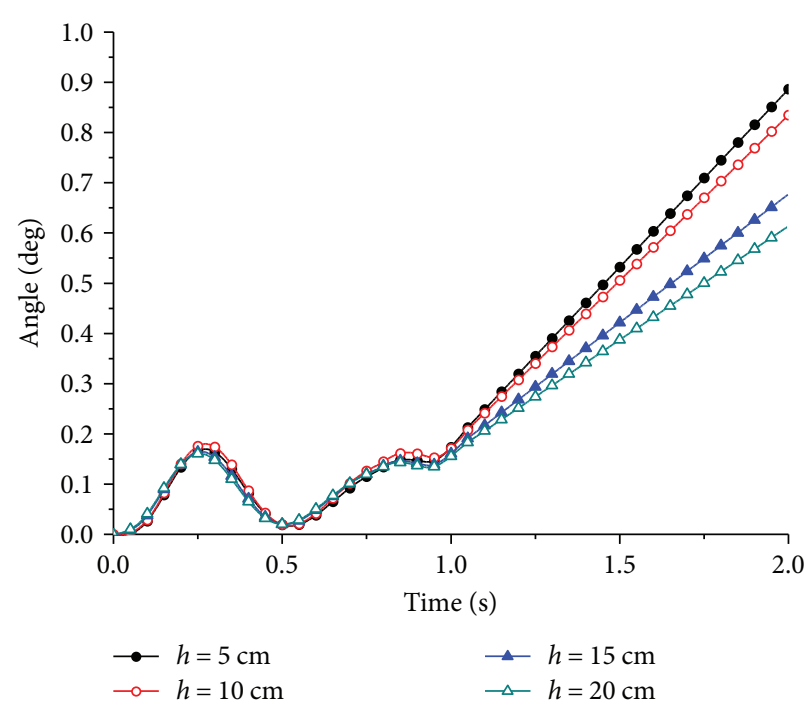

FIgURE 17: Pitch angle of the missile in different surface layer thicknesses.

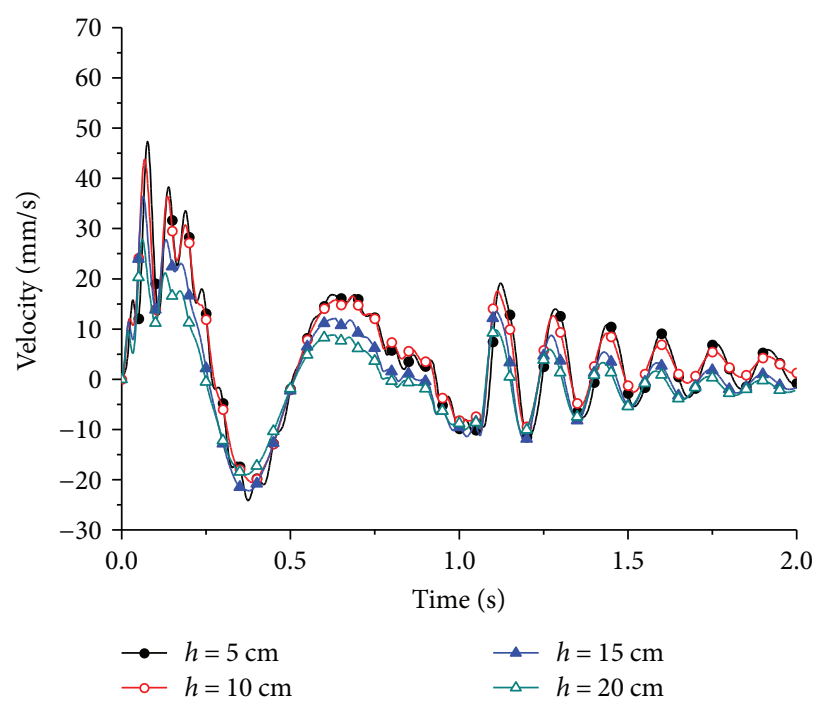

FIgURE 18: Vertical velocity of launch canister top in different surface layer thicknesses.

seen in the data above, the pitch angular velocity and angle when the missile leaves the canister increase along with the decrease of the thickness of the surface layer, but there is no significant proportion relationship between them.

Figures 18 and 19 show the vertical velocity and displacement curves of launch canister top in different surface layer thicknesses, respectively. Figures 20 and 21 show curves of longitudinal velocity and displacement of launch canister top in different surface layer thicknesses, respectively.

3.3.3. Influence on Launch Effect of the Elastic Modulus of Concrete Surface Layer. The influence of the elastic modulus of the concrete panel on launch effect is discussed here. Based on the basic field floor structure, the elastic modulus of the panel is taken as $10000 \mathrm{MPa}, 20000 \mathrm{MPa}, 30000 \mathrm{MPa}$, and 


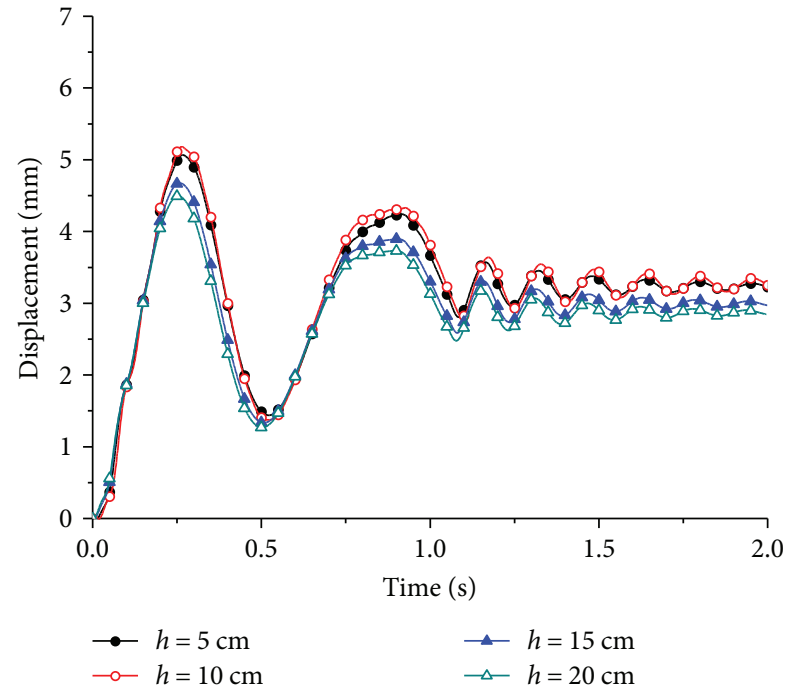

FIgURE 19: Vertical displacement of launch canister top in different surface layer thicknesses.

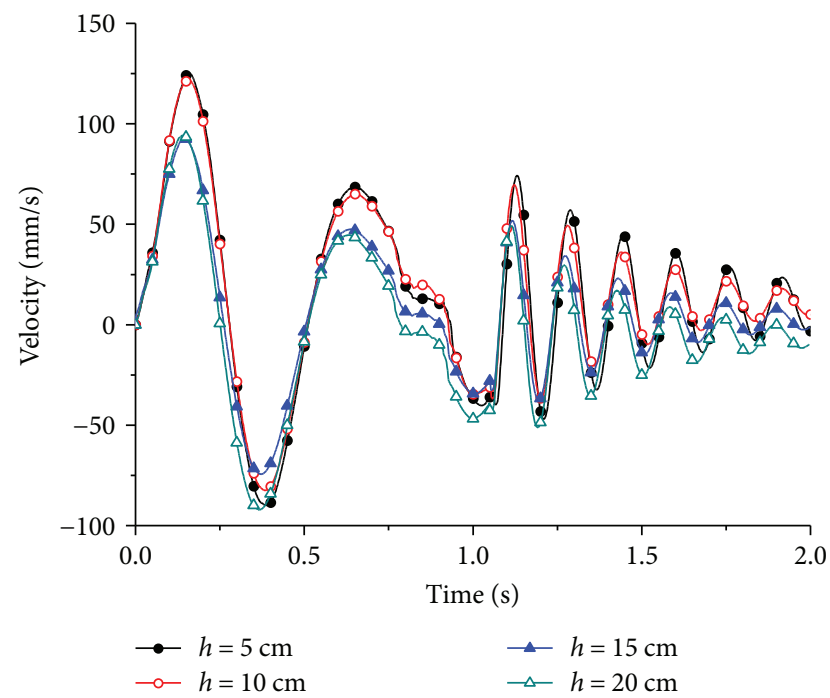

FIGURE 20: Longitudinal velocity of launch canister top in different surface layer thicknesses.

$40000 \mathrm{MPa}$ to carry out the launch dynamic simulations. The calculations are as follows.

Figure 22 shows curves of missile velocity at different elastic modulus of the surface layer, from which it can be seen that the curves are almost identical, and the maximum velocities are all $26.60 \mathrm{~m} / \mathrm{s}$; the effect of Young's modulus on average velocity and the final velocity can be seen from Table 3, illustrating that the elastic modulus of the concrete surface layer of the field floor has no effect on the missile's velocity when leaving the canister.

The curves in Figures 23 and 24 show the pitch angular velocities and angular displacements of the missile at different elastic modulus. It can be seen that the pitch angular

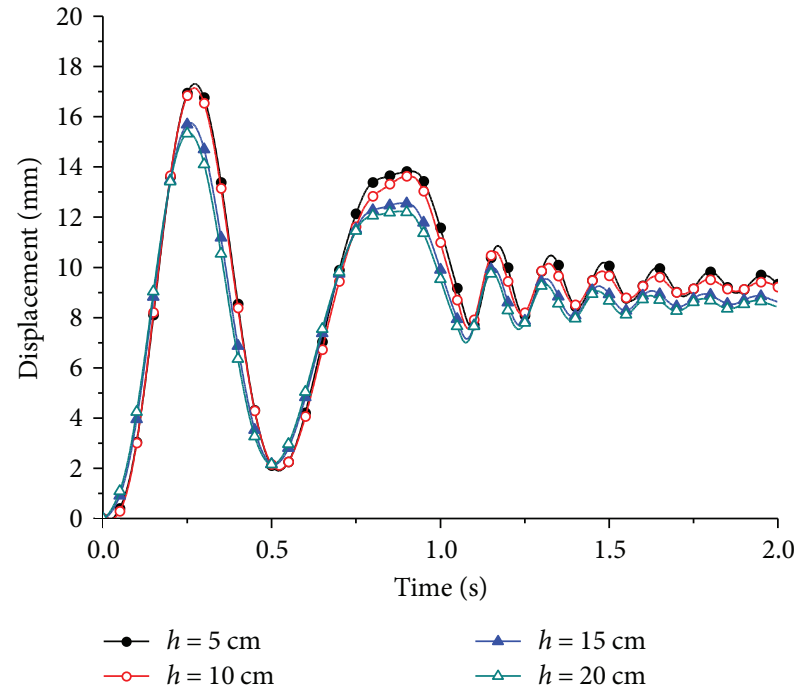

FIGURE 21: Longitudinal displacement of launch canister top in different surface layer thicknesses.

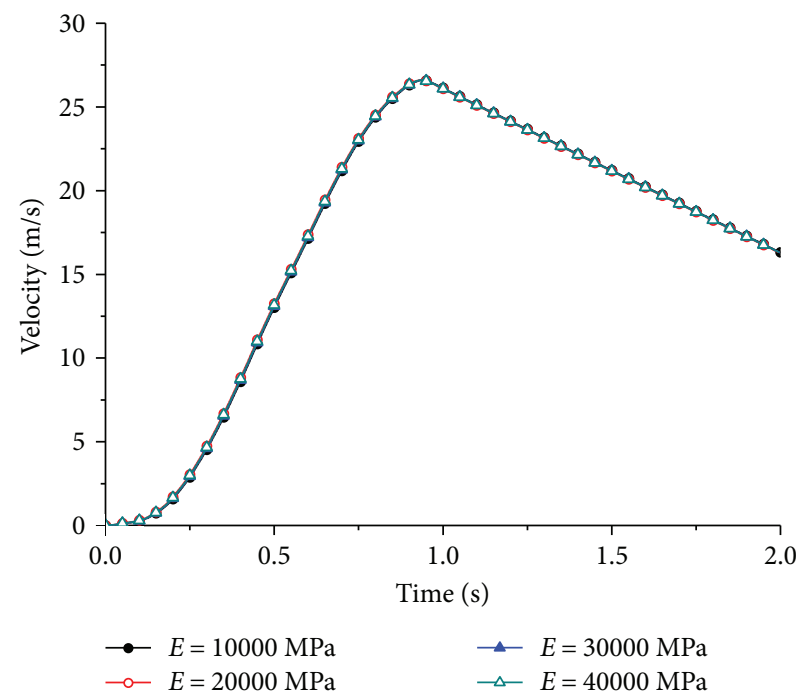

FIgURE 22: Velocity of the missile when leaving the canister at different elastic modulus.

TABLE 3: The effect of elastic modulus on velocity.

\begin{tabular}{lcc}
\hline Elastic modulus (MPa) & $\begin{array}{c}\text { Average velocity } \\
(\mathrm{m} / \mathrm{s})\end{array}$ & $\begin{array}{c}\text { Final velocity } \\
(\mathrm{m} / \mathrm{s})\end{array}$ \\
\hline 10,000 & 17.11 & 16.31 \\
20,000 & 17.16 & 16.31 \\
30,000 & 17.13 & 16.30 \\
40,000 & 17.14 & 16.31 \\
\hline
\end{tabular}

velocity and the angle of the missile at different elastic modulus is also not the same. When leaving the launch canister, the pitch angular velocities at different elastic modulus are $0.559 \mathrm{deg} / \mathrm{s}, 0.496 \mathrm{deg} / \mathrm{s}, 0.393 \mathrm{deg} / \mathrm{s}$, and $0.321 \mathrm{deg} / \mathrm{s}$; and 


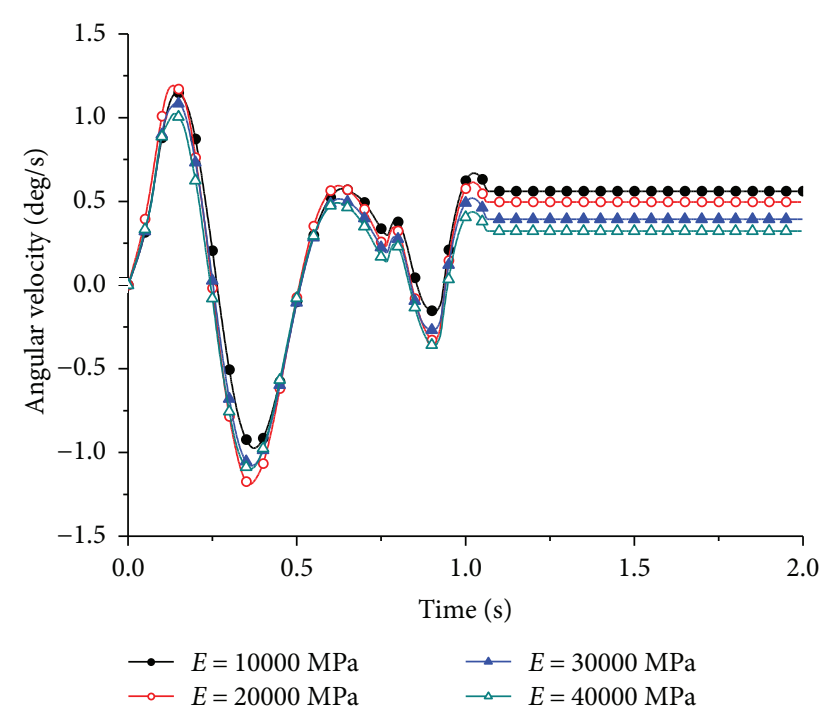

FIGURE 23: Pitch angular velocity of the missile at different elastic modulus.

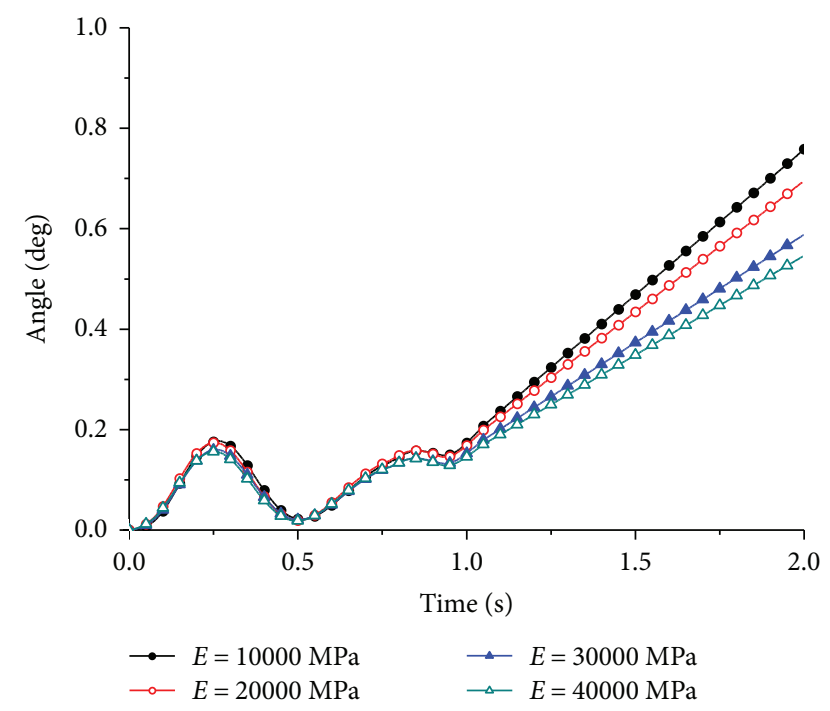

FIgURE 24: Pitch angle of the missile at different elastic modulus.

the angular displacements are $0.218 \mathrm{deg}, 0.209 \mathrm{deg}, 0.187 \mathrm{deg}$, and $0.177 \mathrm{deg}$, respectively. Further calculation shows modulus 1, 2, and 3 compared with modulus 4 reduces $75 \%, 50 \%$, and $25 \%$, respectively. The pitch angular velocity of the missile when leaving the canister increases $74.10 \%, 54.50 \%$, and $22.40 \%$, while the pitch angular displacement increases $23.20 \%, 17.50 \%$ and $5.60 \%$, respectively. From the data above, it can be seen that the pitch angular velocity and angular displacement of the missile when leaving the canister both increase with the decrease of the elastic modulus of the surface layer, wherein the pitch angular velocity and the elastic modulus are approximately in proportional relationship.

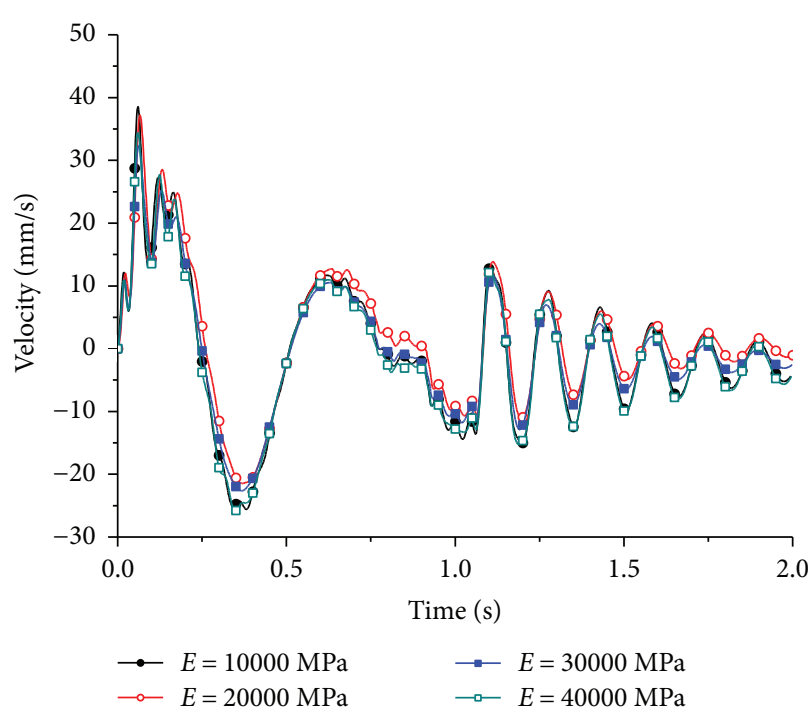

FIgURE 25: Vertical velocity of launch canister top at different elastic modulus.

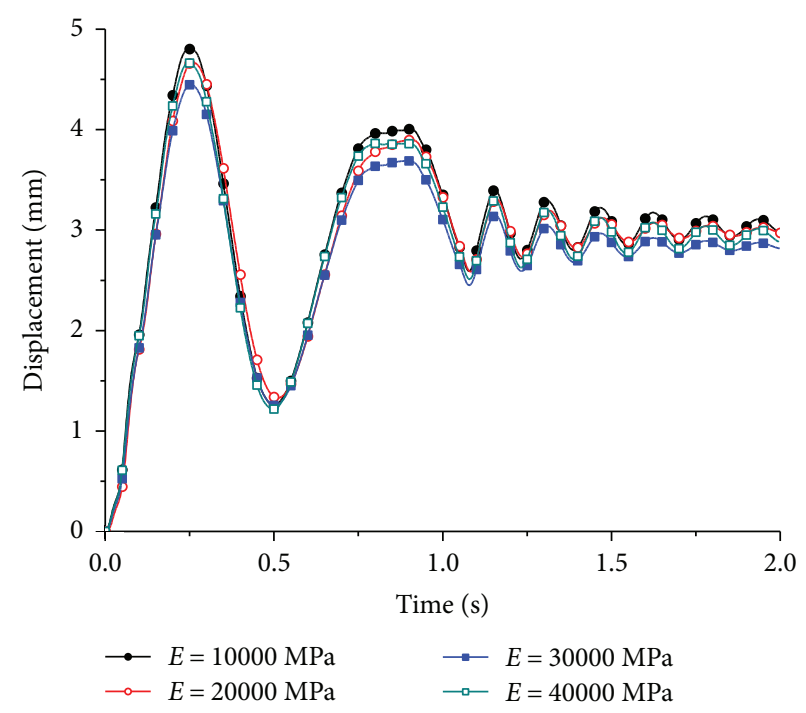

FIgURE 26: Vertical displacement of launch canister top at different elastic modulus.

Figures 25 and 26 shows curves of vertical velocity and displacement of launch canister top at different elastic modulus. The curves in Figures 27 and 28 show the longitudinal velocities and displacement of launch canister top at different elastic modulus. From the four graphs above, there are no significant changes in the vertical and longitudinal movements of the canister top along with the increase of the elastic modulus, and the curves are almost identical. As is concluded in the last section, the thickness of the surface layer has a greater effect on the vibration of the launch platform.

It can be concluded that the elastic modulus has a smaller effect on the supporting role of the field floor compared with the thickness of the surface layer. 


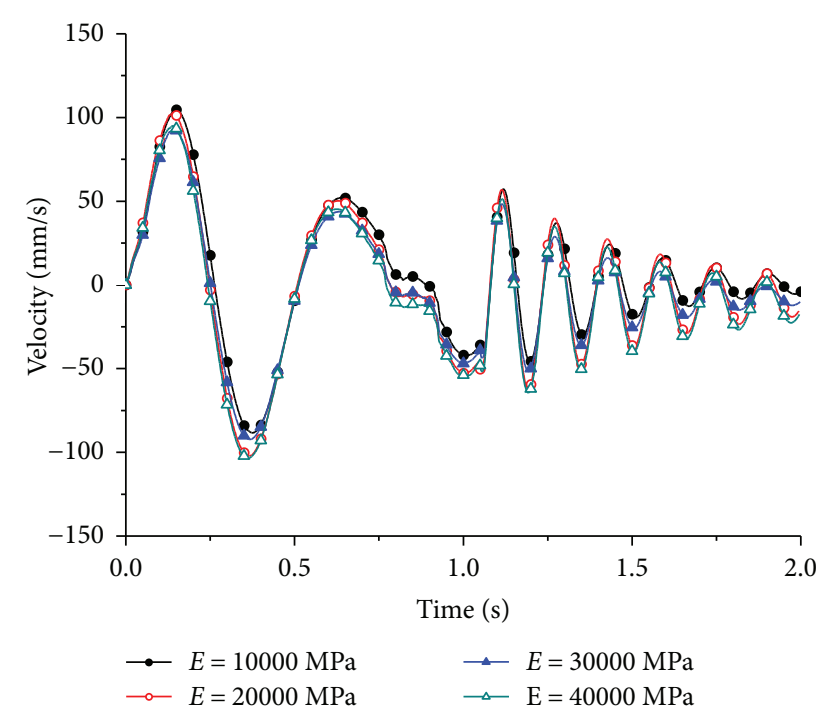

FIGURE 27: Longitudinal velocity of launch canister top at different elastic modulus.

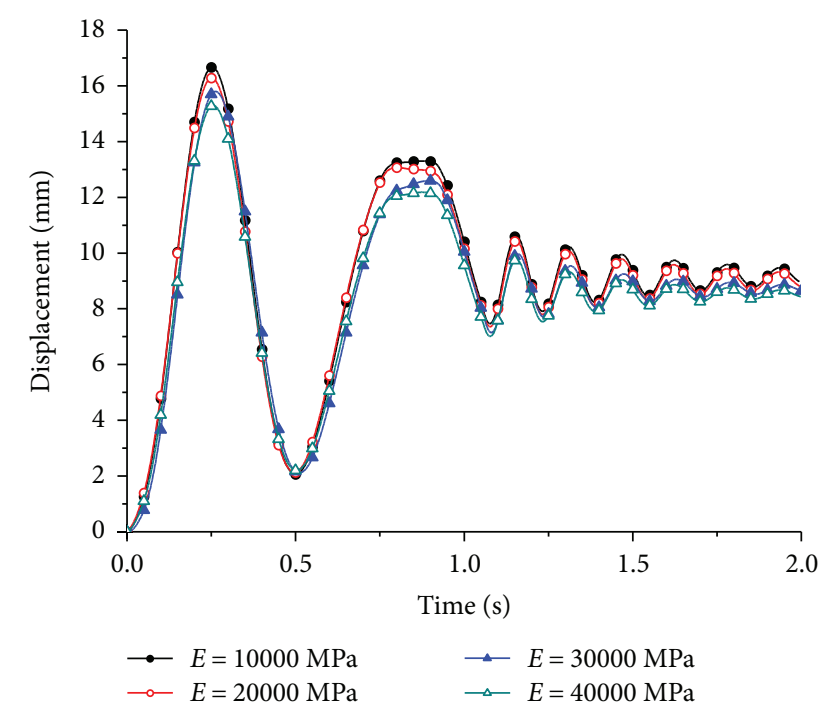

FIGURE 28: Longitudinal displacement of launch canister at different elastic modulus.

\section{Conclusion}

During the launch process of vehicle missile without relying on field floor, it is better to choose the pavement with a thickness more than $20 \mathrm{~cm}$ of the surface layer to work for the purpose of reducing the initial disturbance when launching. Compared with the thickness of the surface layer, the elastic modulus of it has a smaller effect on the supporting role of the field floor. As a consequence, when selecting the concrete pavement as the field floor, the thickness of the surface layer should be considered in priority, secondly is the elastic modulus.

\section{Conflicts of Interest}

The authors declare that they have no conflicts of interest.

\section{References}

[1] A. Losberg, Structurally Reinforced Concrete Pavements [Ph.D. thesis], Chalmers University of Technology, Gothenburg, Sweden, 1960.

[2] G. G. Meyerhof, "Some recent research on the bearing capacity of foundations," Canadian Geotechnical Journal, vol. 1, no. 1, pp. 16-26, 1963.

[3] X. J. Deng and R. S. Chen, Rigid Pavement Design, China Communication Press, Beijing, China, 2nd edition, 2005.

[4] Q. H. Gao and C. L. Ma, Modeling and Simulation Technology and Application of Dynamic Characteristics of Hydraulic System, Publishing House of Electronics Industry, Beijing, China, 2013.

[5] C. Z. Liu, Research of Medium Erecting Device, Huazhong University of Science and Technology, Hubei, China, 2007.

[6] Y. F. Dai, "Hydraulic stiffness calculation of hydraulic cylinder," Non-ferrous Metal Design, vol. 26, no. 1, pp. 61-63, 1999.

[7] H. Liu, X. C. Ni, and J. Bai, “Additional load study during the drape launch of adaptive base," Missiles and Space Vehicles, vol. 03, pp. 23-25, 2012.

[8] J. L. Zhong, J. Ren, and D. W. Ma, "Research on mechanical properties of adaptive base based on micromechanics accurate modeling method," Solid Rocket Technology, vol. 03, pp. 400407, 2014. 


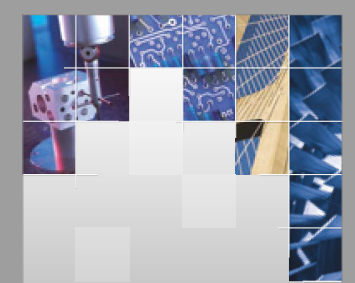

\section{Enfincering}
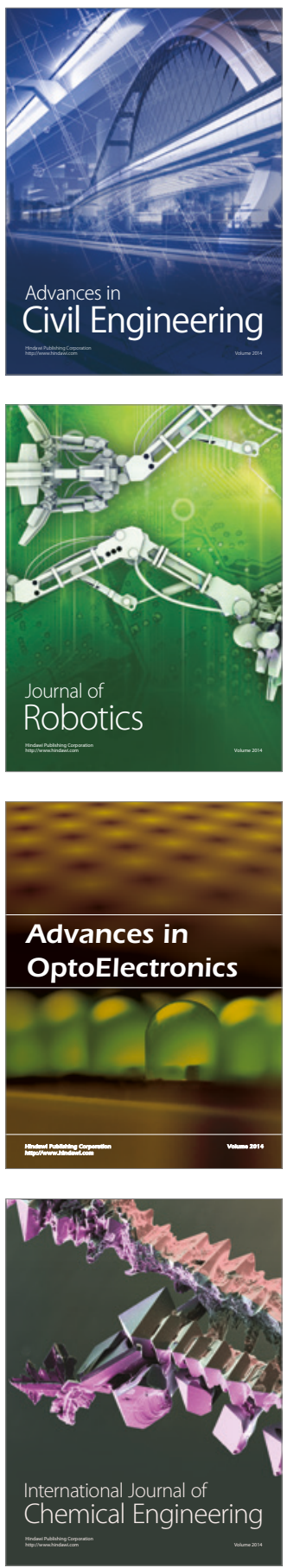

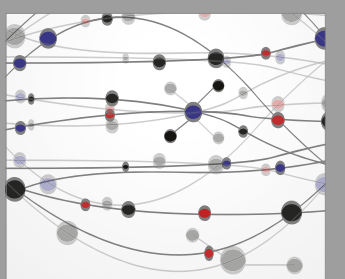

The Scientific World Journal

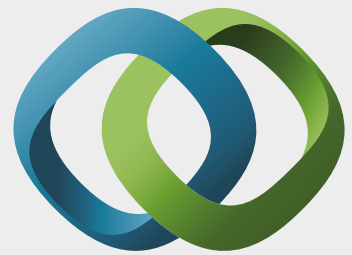

\section{Hindawi}

Submit your manuscripts at

https://www.hindawi.com
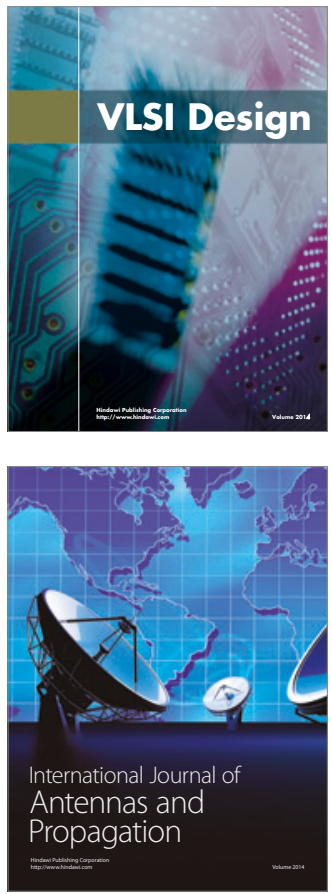

\section{Rotating}

Machinery
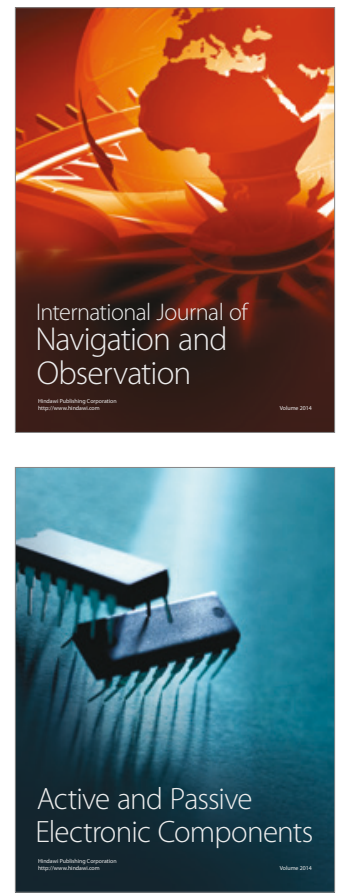
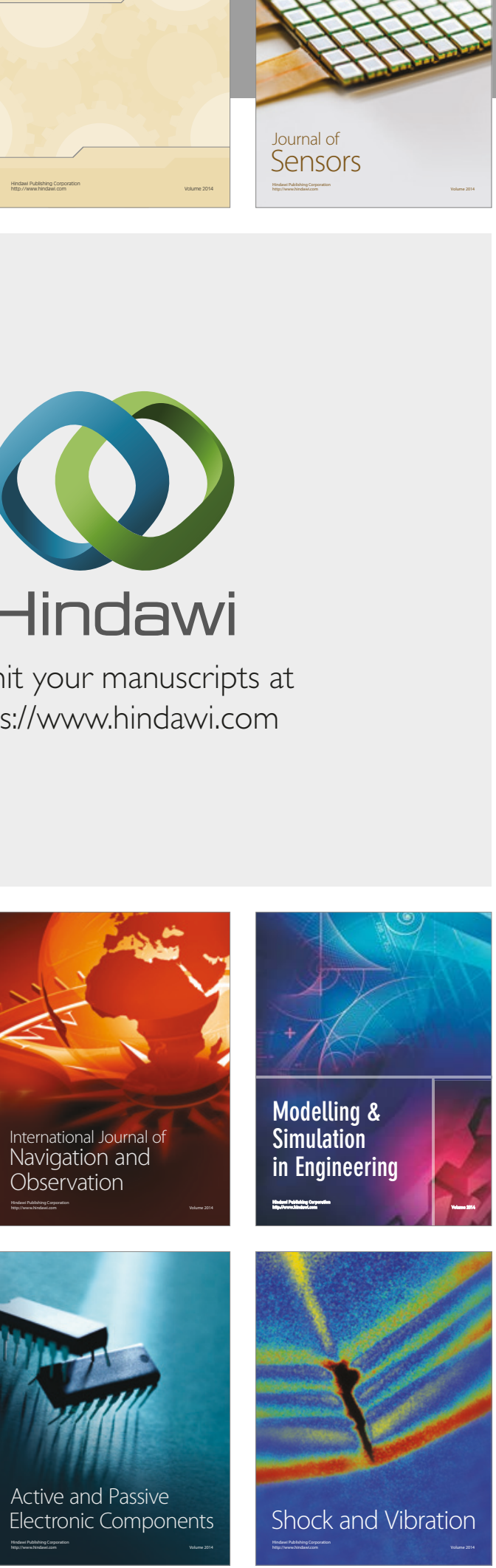
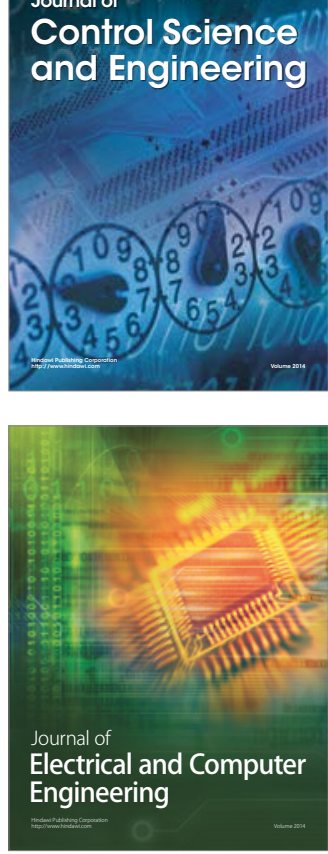

Distributed

Journal of

Control Science

and Engineering
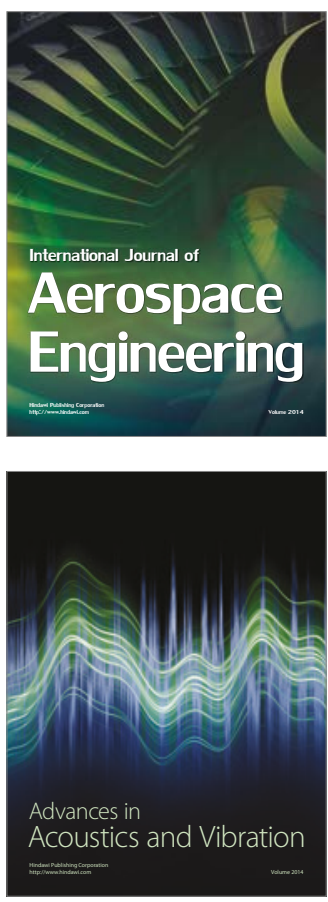

Sensor Networks 